\title{
Comparison of erlotinib and pemetrexed as second-I third-line treatment for lung adenocarcinoma patients with asymptomatic brain metastases
}

This article was published in the following Dove Press journal:

OncoTargets and Therapy

21 April 2016

Number of times this article has been viewed

\author{
Yayi $\mathrm{He}^{1, *}$ \\ Wenwen Sun ${ }^{2, *}$ \\ Yan Wang ${ }^{3, *}$ \\ Shengxiang Ren' \\ Xuefei $\mathrm{Li}^{3}$ \\ Jiayu $\mathrm{Li}^{3}$ \\ Christopher J Rivard ${ }^{4}$ \\ Caicun Zhou' \\ Fred R Hirsch ${ }^{4}$ \\ 'Department of Oncology, Shanghai \\ Pulmonary Hospital, ${ }^{2}$ Clinic and \\ Research Center of Tuberculosis, \\ Shanghai Key Laboratory of \\ Tuberculosis, Shanghai Pulmonary \\ Hospital, ${ }^{3}$ Department of Lung \\ Cancer and Immunology, Shanghai \\ Pulmonary Hospital, Tongji University \\ Medical School Cancer Institute, \\ Tongji University School of Medicine, \\ Shanghai, People's Republic of China; \\ ${ }^{4}$ Division of Medical Oncology, \\ Department of Medicine, University \\ of Colorado, Aurora, CO, USA
}

*These authors contributed equally to this work
Objective: Brain metastases occur in one-third of all non-small-cell lung cancer patients. Due to restrictive transport at the blood-brain barrier, many drugs provide poor control of metastases in the brain. The aim of this study was to compare erlotinib with pemetrexed as second-/third-line treatment in patients with lung adenocarcinoma with asymptomatic brain metastases.

Methods: From January 2012 to June 2014, all lung adenocarcinoma patients with asymptomatic brain metastases who received treatment with erlotinib or pemetrexed as second-/third-line treatment were retrospectively reviewed. Chi-square and log-rank tests were used to perform statistical analysis.

Results: The study enrolled 99 patients, of which 44 were positive for EGFR mutation. Median progression-free survival (PFS) in months was not significantly different between the erlotiniband pemetrexed-treated groups (4.2 vs 3.4 months; $95 \%$ confidence interval [CI]: $2.01-6.40$ vs 2.80-5.00, respectively; $P=0.635$ ). Median PFS was found to be significantly longer in $E G F R$ mutation-positive patients in the erlotinib-treated group (8.0 months; 95\% CI 5.85-10.15) compared to the pemetrexed group ( 3.9 months; $95 \% \mathrm{CI}: 1.25-6.55 ; P=0.032$ ). The most common treatment-related side effect was mild-to-moderate rash and the most common drug-related side effects in the pemetrexed-group were vomiting and nausea.

Conclusion: Erlotinib and pemetrexed may be used as second-/third-line treatment in lung adenocarcinoma patients with asymptomatic brain metastases, and detection of EGFR mutation status is very important in these patients. EGFR mutation-positive lung adenocarcinoma patients with asymptomatic brain metastases showed longer PFS when treated with erlotinib as opposed to pemetrexed.

Keywords: erlotinib, pemetrexed, lung adenocarcinoma, EGFR, asymptomatic brain metastases

\section{Introduction}

Lung cancer continues to be the primary cancer-related cause of death worldwide. ${ }^{1-3}$ In majority of cases, lung cancers reach metastatic stage by the time of diagnosis. Brain is one of the most common metastatic sites of lung cancer. ${ }^{4}$ Patients with brain metastases have poor prognoses despite treatment with whole-brain radiotherapy (WBRT) ${ }^{5,6}$ Apart from WBRT, few treatment options are currently available for brain metastases. Most of the potential chemotherapy agents cannot effectively penetrate the blood-brain barrier (BBB). ${ }^{7}$ Therefore, more effective, less toxic treatments are urgently needed for lung adenocarcinoma patients with brain metastases.

Epidermal growth factor receptor tyrosine kinase inhibitors (EGFR-TKIs) have been widely used in the treatment of advanced non-small-cell lung cancer (NSCLC). ${ }^{8-10}$
Correspondence: Caicun Zhou Department of Oncology, Shanghai Pulmonary Hospital, Tongji University School of Medicine, 507 Zhengmin Road, Shanghai, People's Republic of China Tel +86 I330I825532

Email caicunzhoudr@163.com (c) (1) (2) 2016 He et al. This work is published and licensed by Dove Medical Press Limited. The full terms of this license are available at https://www.dovepress.com/terms.php
and incorporate the Creative Commons Attribution - Non Commercial (unported, v3.0) License (http:///creativecommons.org/licenses/by-nd/3.0/). By accessing the work you

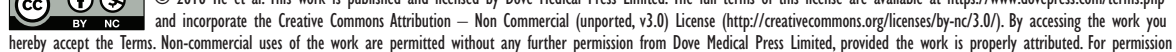
for commercial use of this work, please see paragraphs 4.2 and 5 of our Terms (https://www.dovepress.com/terms.php). 
Patients treated with erlotinib survived longer than those who received best supportive care in second-/third-line therapy. ${ }^{11}$ Many reports have demonstrated that brain metastases of lung adenocarcinoma can respond to EGFR-TKIs. ${ }^{9,12}$

Some clinical trials have also shown that pemetrexed may be effective against brain metastases. Pemetrexed is a third-generation drug that inhibits multiple folate-dependent enzymes. ${ }^{13-15}$ It has been suggested that concomitant treatment of pemetrexed and cisplatin (AP) and WBRT is well tolerated, with promising effects in lung adenocarcinoma patients with brain metastases. ${ }^{15}$

Few studies have compared the therapeutic effects of erlotinib versus pemetrexed in the treatment of lung adenocarcinoma with asymptomatic brain metastases. This study, therefore, aimed to evaluate the efficacy of erlotinib compared with pemetrexed as second-/third-line therapy in lung adenocarcinoma patients with asymptomatic brain metastases.

\section{Patients and methods Patients}

From January 2012 to June 2014, 99 patients were enrolled into the study. Eligible patients were confirmed with stage IV lung adenocarcinoma (Union for International Cancer Control classification version 7) with a confirmed activating mutation of EGFR (exon 19 deletion or an exon 21 L858R mutation). Patients were all in second-/third-line chemotherapy treatment and had platinum-based doublet chemotherapy as first-line therapy. All patients also had measurable disease according to Response Evaluation Criteria in Solid Tumors (RECIST version 1.1), an Eastern Cooperative Oncology Group performance status of $0-2$, adequate hematological, biochemical, and organ function, and were above 18 years old. This research was approved by the Ethics Committee of Shanghai Pulmonary Hospital, Tongji University, and written informed consent was obtained from all of the enrolled patients.

\section{Treatment}

Patients' data include medical history and physical examination, hematologic and biochemical testing, and chest and abdomen computed tomographic scans before second-/thirdline treatment. Assessments of toxic effects and quality of life were obtained. Patients received erlotinib, $150 \mathrm{mg}$ daily, or pemetrexed, $500 \mathrm{mg} / \mathrm{m}^{2}$ day 1 , which was repeated every 3 weeks until disease progression or intolerable side effects occurred. Toxicity was assessed according to National Cancer Institute Common Toxicity Criteria (version 4.0). Patients were evaluated every 3 weeks, at which time hematology and blood chemistry assessments were performed; tumor measurements were made every 6 weeks.

\section{DNA extraction and EGFR mutation analysis}

All EGFR mutational analyses were performed by Amplification Refractory Mutation System in Tongji University Medical School Cancer Institute (Shanghai, People's Republic of China), as described previously. ${ }^{16}$

\section{Statistical analysis}

The chi-square test was used to analyze the association between hepatic metastases, clinical data, and disease control rate. For the survival analysis, patients were censored at the last date at which they were known to be alive. All time-to-event outcomes, such as progression-free survival (PFS), were estimated using the Kaplan-Meier method and compared across groups with the log-rank test or the Cox proportional hazards model. The SPSS statistical package for Windows version 17.0 (SPSS Inc., Chicago, IL, USA) was used. All $P$-values were two-sided, and statistical significance was defined as $P<0.05$.

\section{Results}

\section{Patient characteristics}

A total of 99 lung adenocarcinoma patients with asymptomatic brain metastases with known EGFR mutation status were enrolled into the study. Of these patients, 68 received erlotinib and 31 received pemetrexed. The median age was 56 years, and $36(36.4 \%)$ were males and 63 (63.6\%) were females. Among all patients, 44 (47.1\%) had an EGFR positive mutation. Among patients with a positive $E G F R$ mutation, 32 patients were treated with erlotinib and 12 patients with pemetrexed. None of the patients had received WBRT before enrolling into the study. Table 1 summarizes the characteristics of the eligible patients.

\section{Therapeutic effects}

In the erlotinib-treated group $(n=68)$, the objective response rates of cerebral and extracerebral lesions were found to be similar ( $29.4 \%$ vs $26.5 \% ; P=0.134)$. In the pemetrexedtreated group $(n=31)$, no statistical difference was observed between the response rates of cerebral and extracerebral lesions ( $12.9 \%$ vs $16.1 \%$; $P=0.525$; Table 2$)$. In the erlotinibtreated group $(n=68)$, the objective control rates of cerebral and extracerebral lesions showed significant difference $(P=0.000$; Table 3$)$. 
Table I Characteristics of eligible patients

\begin{tabular}{ll}
\hline Sex, $\mathrm{n}(\%)$ & \\
$\quad$ Male & $36(36.4)$ \\
Female & $63(63.6)$ \\
Age, median & 56 \\
Smoker, $\mathrm{n}(\%)$ & $40(40.4)$ \\
Performance status (ECOG), $\mathrm{n}(\%)$ & \\
0 & $2(2.0)$ \\
$\mathrm{I}$ & $77(77.8)$ \\
2 & $20(20.2)$ \\
T stage, $\mathrm{n}(\%)$ & \\
I & $3(3.0)$ \\
2 & $27(27.3)$ \\
3 & $19(19.2)$ \\
4 & $50(50.5)$ \\
$\mathrm{N}$ stage, $\mathrm{n}$ (\%) & \\
0 & $2(2.0)$ \\
I & $15(15.2)$ \\
2 & $59(59.6)$ \\
3 & $23(23.2)$ \\
EGFR mutation, $\mathrm{n}(\%)$ & $44(44.4)$ \\
Exon I9 deletion & $24(54.5)$ \\
Exon 2 I mutation & $20(45.5)$ \\
Number of brain metastases, $\mathrm{n}(\%)$ & \\
$\leq 3$ & $42(42.4)$ \\
$<3$ & $57(57.6)$ \\
\hline Abbreviation: ECOG, Eastern Cooperative Oncology Group. &
\end{tabular}

Abbreviation: ECOG, Eastern Cooperative Oncology Group.

\section{Association between EGFR mutation and clinicopathological features}

$E G F R$-positive mutations were more prevalent in nonsmokers (33 patients, 33.3\%) than smokers $(11.1 \%)(P=0.005)$. No significant difference was observed between male and female patients $(P=0.582)$.

\section{Survival analysis}

Figure 1 shows the Kaplan-Meier curve for PFS. Median PFS was not different between the groups treated with erlotinib and pemetrexed (4.2 vs 3.4 months; 95\% confidence intervals $[\mathrm{CI}]: 2.01-6.40$ vs $2.80-5.00$, respectively; $P=0.635$ ) (Figure 1).

Table 2 Therapeutic effect in different tumor lesion (PD + SD versus $P R+C R$ )

\begin{tabular}{lllll}
\hline Therapy & $\begin{array}{l}\text { Extracerebral } \\
\text { lesions }\end{array}$ & \multicolumn{2}{l}{$\begin{array}{l}\text { Cerebral lesions, } \\
\mathbf{n}(\%)\end{array}$} & \multirow{2}{*}{-value } \\
\cline { 3 - 4 } & & PD + SD & PR + CR & \\
\hline Erlotinib & PD + SD & $38(55.9)$ & $12(17.6)$ & 0.134 \\
& PR + CR & $10(14.7)$ & $8(11.8)$ & \\
Pemetrexed & PD + SD & $23(74.2)$ & $3(9.7)$ & 0.525 \\
& PR + CR & $4(12.9)$ & I (3.2) & \\
\hline
\end{tabular}

Abbreviations: PD, progressive disease; SD, stable disease; PR, partial response; $\mathrm{CR}$, complete response.
Table 3 Therapeutic effects in different tumor lesion (CR + PR + SD versus $P D$ )

\begin{tabular}{lllll}
\hline Therapy & $\begin{array}{l}\text { Extracerebral } \\
\text { lesions }\end{array}$ & $\begin{array}{l}\text { Cerebral lesions, } \\
\mathbf{n}(\%)\end{array}$ & \multirow{2}{*}{ P-value } \\
\cline { 3 - 4 } & & $\mathbf{P R}+\mathbf{C R}+\mathbf{S D}$ & $\mathbf{P D}$ & \\
\hline Erlotinib & PR + CR + SD & $43(63.2)$ & $6(8.8)$ & 0.000 \\
& PD & $7(10.3)$ & $12(17.6)$ & \multirow{2}{*}{ Pemetrexed } \\
& PR + CR + SD & $19(61.3)$ & $10(32.3)$ & 0.142 \\
& PD & $0(12.9)$ & $2(6.5)$ & \\
\hline
\end{tabular}

Abbreviations: $\mathrm{PD}$, progressive disease; $\mathrm{SD}$, stable disease; $\mathrm{PR}$, partial response; $\mathrm{CR}$, complete response.

In the erlotinib-treated group, median PFS in EGFR mutation-positive patients was 8.0 months, whereas it was 1.3 months in EGFR mutation-negative patients $(95 \%$ CI: $5.85-10.15$ vs $0.26-2.35 ; P<0.001$ ) (Figure 2). The median PFS in EGFR mutation-positive patients was 8.0 months in the erlotinib-treated group, whereas it was 3.9 months in the pemetrexed-treated group (95\% CI: $5.85-10.15$ vs $1.25-6.55$; $P=0.032)$. These two sentences are repetitive regarding PFS in mutation-positive patients with erlotinib.

\section{Treatment-related side effects}

The most frequent treatment-related side effects observed with erlotinib therapy were mild-to-moderate skin toxicity (48.5\%), diarrhea $(27.9 \%)$, and increased levels of alanine aminotransferase (23.5\%). Patients experienced grade 3-4 events including two cases of anemia, three cases of skin rash, one case of increased alanine aminotransferase levels, and two cases of fatigue. The most common drug-related side effects observed in the pemetrexed-treated group were

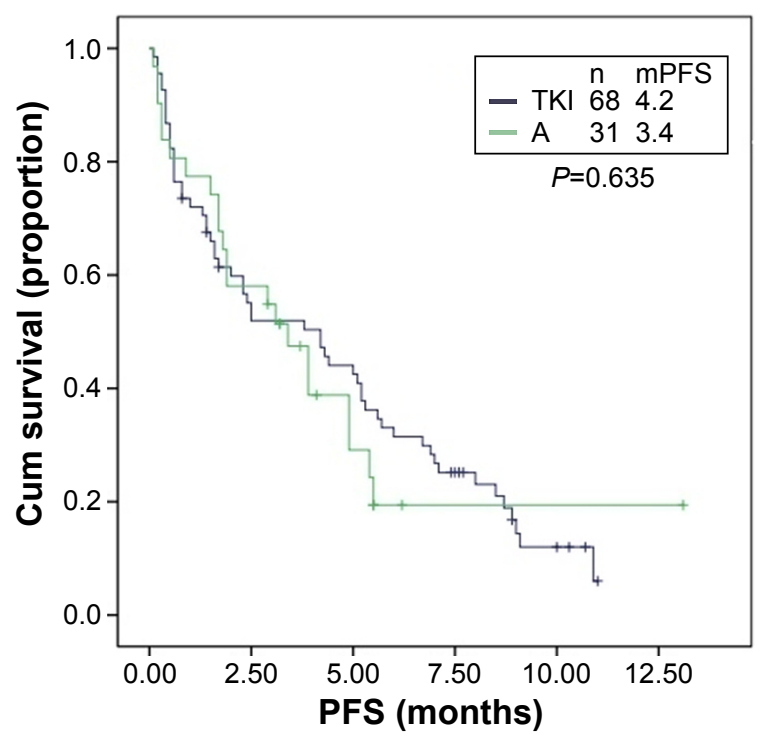

Figure I Association between therapeutic effect and PFS in patients.

Abbreviations: PFS, progression-free survival; TKI, erlotinib; A, pemetrexed; mPFS, PFS (month). 


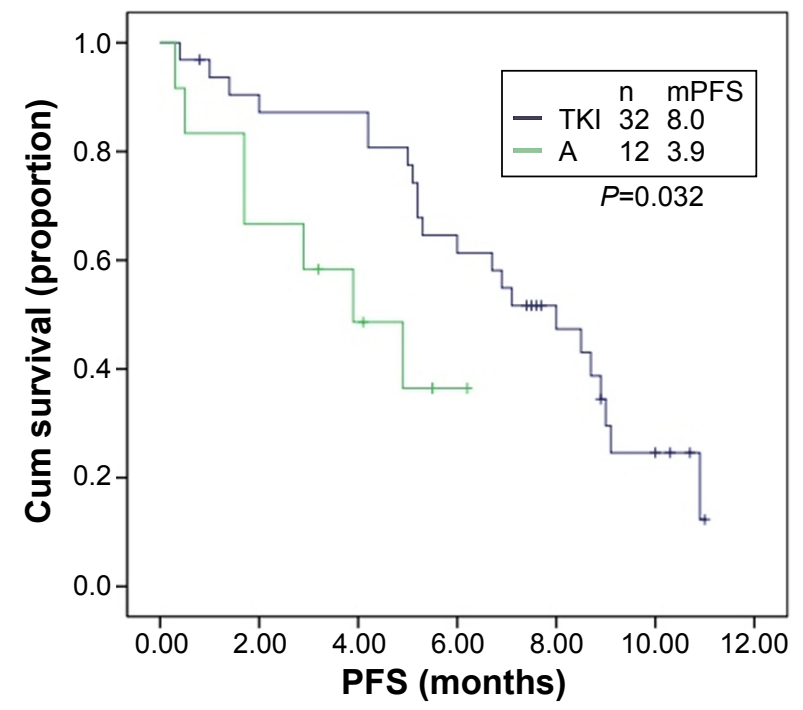

Figure 2 Association between therapeutic effect and PFS in EGFR mutation-positive patients.

Abbreviations: PFS, progression-free survival; TKI, erlotinib; A, pemetrexed; mPFS, PFS (month).

vomiting or nausea $(9.7 \%)$, and one patient experienced grade 3 fatigue (Table 4 ).

\section{Discussion}

This study investigated the efficacy of erlotinib compared with pemetrexed as second-/third-line treatment in lung adenocarcinoma with asymptomatic brain metastases in Chinese patients. We found that these drugs may be used as second-/third-line treatment in these patients. In EGFR mutation-positive patients with lung adenocarcinoma and asymptomatic brain metastases, treatment with erlotinib yielded longer median PFS.

The brain is a common site of NSCLC metastases: $50 \%$ of patients with lung cancer eventually experience

Table 4 Treatment-related side effects

\begin{tabular}{|c|c|c|c|c|}
\hline \multirow[t]{2}{*}{ Toxicity } & \multicolumn{2}{|l|}{ Erlotinib } & \multicolumn{2}{|c|}{ Pemetrexed } \\
\hline & $\begin{array}{l}\text { Any grade, } \\
\text { n (\%) }\end{array}$ & $\begin{array}{l}\text { Grade } \\
3 \text { or } 4 \text {, } \\
\text { n (\%) }\end{array}$ & $\begin{array}{l}\text { Any grade, } \\
\text { n (\%) }\end{array}$ & $\begin{array}{l}\text { Grade } \\
3 \text { or } 4, \\
n(\%)\end{array}$ \\
\hline Neutropenia & $3(4.4)$ & $0(0.0)$ & $2(6.5)$ & $0(0.0)$ \\
\hline Thrombocytopenia & $4(5.9)$ & $0(0.0)$ & $0(0.0)$ & $0(0.0)$ \\
\hline Anemia & $4(5.9)$ & $2(2.9)$ & $2(6.5)$ & $0(0.0)$ \\
\hline Infection & $0(0.0)$ & $0(0.0)$ & $0(0.0)$ & $0(0.0)$ \\
\hline Skin rash & $33(48.5)$ & $3(4.4)$ & $0(0.0)$ & $0(0.0)$ \\
\hline Diarrhea & $19(27.9)$ & $0(0.0)$ & $0(0.0)$ & $0(0.0)$ \\
\hline Stomatitis & $9(13.2)$ & $0(0.0)$ & I (3.2) & $0(0.0)$ \\
\hline Paronychia & $10(14.7)$ & $0(0.0)$ & $0(0.0)$ & $0(0.0)$ \\
\hline Vomiting or nausea & $7(10.3)$ & $0(0.0)$ & $3(9.7)$ & $0(0.0)$ \\
\hline Increased ALT & $16(23.5)$ & $\mathrm{I}(\mathrm{I} .5)$ & $2(6.5)$ & $0(0.0)$ \\
\hline Fatigue & II (I6.2) & $2(2.9)$ & $2(6.5)$ & I (3.2) \\
\hline
\end{tabular}

Abbreviation: ALT, alanine aminotransferase. brain metastases. ${ }^{17}$ Available therapeutic approaches for brain metastases include WBRT, stereotactic radiosurgery, surgery, and supportive treatment. ${ }^{18-20}$ Despite advances in NSCLC treatment, survival rates for brain metastases patients are still poor. ${ }^{19}$ Most brain metastases from NSCLC are not treatable by surgery when they are diagnosed, ${ }^{21}$ so WBRT represents the standard treatment. The treatment of NSCLC patients with brain metastases remains a significant challenge.

Erlotinib and gefitinib have been widely used in advanced NSCLC. ${ }^{8-10}$ However, not all patients are sensitive to the EGFR-TKIs. The response rate is from $10 \%$ to $40 \%{ }^{22,23}$ Patients of East Asian ethnicity, nonsmokers, and those with adenocarcinoma may benefit more from the EGFR-TKIs treatment. ${ }^{24}$ Our study results concur with former studies, ${ }^{16,25}$ which showed that EGFR-positive mutations were more prevalent in nonsmokers than smokers. ${ }^{26,27}$

Some scientists have reported high concentrations of erlotinib in the cerebrospinal fluid and subsequent regression of brain metastases with the treatment of erlotinib. ${ }^{28-30}$ Erlotinib passes into the cerebrospinal fluid in concentrations sufficient to cause brain metastasis regression. ${ }^{31-36}$ Regression of both the primary lung tumor and brain metastases in EGFR mutation-positive patients was reported in a positron emission tomography study using $\mathrm{C} 11$ erlotinib. ${ }^{30}$ Weekly high-dose "pulses" of erlotinib could increase the concentration of erlotinib in the cerebrospinal fluid..$^{35,36}$ Meanwhile, several studies concluded that the presence of EGFR mutations is an independent predictor of response to WBRT in brain metastases of lung adenocarcinoma. ${ }^{31-33}$ EGFR-TKIs might have an incomplete penetration though the BBB and its effectiveness for the treatment of brain metastasis may depend on the disruption of the barrier. ${ }^{32,33}$ The CTONG-0803 Phase II study showed that treatment with erlotinib resulted in significantly longer median time to progression within the brain and longer median overall survival among patients with EGFR mutation-positive NSCLC. ${ }^{9}$

Pemetrexed is a third-generation agent that inhibits multiple folate-dependent enzymes. ${ }^{13-15,37}$ It was reported that pemetrexed treatment could reduce the risk of developing brain metastases as the first site of disease progression. The findings suggested a potential beneficial effect of pemetrexed-based treatments for the control of brain metastases. ${ }^{37} \mathrm{~A}$ prospective study demonstrated overall pulmonary and brain clinical benefits when irradiation-naive patients received pemetrexed as second- or 
later-line treatment. ${ }^{38}$ Another study reported $41.9 \%$ and $34.9 \%$ response rates on brain metastases and extracranial disease when pemetrexed plus cisplatin was received as the first-line therapy for NSCLC patients with brain metastases. ${ }^{39}$ Recently, some Phase I and II clinical trials have demonstrated that pemetrexed plus cisplatin can be given concurrently with thoracic radiotherapy at full dose with tolerated toxicities. This combined modality therapy of AP chemotherapy with WBRT was generally well tolerated by most patients. ${ }^{13,14}$ Most side effects were well controlled by supportive care. ${ }^{15}$

Our study found no significant difference in response rates between patients with cerebral and extracerebral lesions. We hypothesize that both erlotinib and pemetrexed pass through the BBB. Patients with EGFR mutation-positive NSCLC who received erlotinib had a higher disease overall response rate and longer PFS than those who received pemetrexed.

In the erlotinib-treated group, the main side effects were rash and diarrhea. Patient's response to erlotinib was correlated with the grade of rash, in agreement with several previous trials. ${ }^{9,34}$ The most common drug-related side effects reported during pemetrexed therapy were vomiting and nausea. EGFR mutation-positive patients with lung adenocarcinoma and asymptomatic brain metastases treated with erlotinib had longer PFS than those who were treated with pemetrexed.

\section{Conclusion}

In conclusion, this study suggests that erlotinib or pemetrexed monotherapy is a potentially promising option with relatively modest side effects for second-/third-line treatment of lung adenocarcinoma patients with asymptomatic brain metastases. In EGFR mutation-positive patients with these symptoms, treatment with erlotinib resulted in longer PFS compared with pemetrexed. Also pemetrexed compared with erlotinib was found to be the better choice of treatment in these patients, in whom EGFR mutation status is also very important to be considered. Further study is needed to compare the overall survival of these patients when treated with erlotinib and pemetrexed.

\section{Acknowledgment}

This study was supported by the Young Program of Shanghai National Health and Family Planning Commission and a grant from the Chronic Disease Comprehensive Prevention and Control Project by Shanghai Shenkang Hospital Development Center (No SHDC12012313).

\section{Disclosure}

The authors report no conflict of interest in this work.

\section{References}

1. Ferlay J, Shin HR, Bray F, et al. Estimates of worldwide burden of cancer in 2008: GLOBOCAN 2008. Int J Cancer. 2010;127(12):2893-2917.

2. Jemal A, Bray F, Center MM, et al. Global cancer statistics. CA Cancer J Clin. 2011;61(2):69-90.

3. Jemal A, Murray T, Ward E, et al. Cancer statistics 2005. CA Cancer J Clin. 2005;55(1):10-30.

4. Sørensen JB, Hansen HH, Hansen M, et al. Brain metastases in adenocarcinoma of the lung: frequency, risk groups, and prognosis. J Clin Oncol. 1988;6(9):1474-1480.

5. Gaspar L, Scott C, Rotman M, et al. Recursive partitioning analysis (RPA) of prognostic factors in three Radiation Therapy Oncology Group (RTOG) brain metastases trials. Int J Radiat Oncol Biol Phys. 1997; 37(4):745-751.

6. Zabel A, Debus J. Treatment of brain metastases from non-small-cell lung cancer (NSCLC): radiotherapy. Lung Cancer. 2004;45(Suppl 2): S247-S252.

7. Grimm SA. Treatment of brain metastases: chemotherapy. Curr Oncol Rep. 2012;14(1):85-90.

8. Namba Y, Kijima T, Yokota S, et al. Gefitinib in patients with brain metastases from non small-cell lung cancer: review of 15 clinical cases. Clin Lung Cancer. 2004;6(2):123-128.

9. Zhou C, Wu YL, Chen G, et al. Erlotinib versus chemotherapy as first-line treatment for patients with advanced EGFR mutation-positive non-small-cell lung cancer (OPTIMAL, CTONG-0802): a multicentre, openlabel, randomised, phase 3 study. Lancet Oncol. 2011; 12(8):735-742.

10. Lee JK, Kim TM, Koh Y, et al. Differential sensitivities to tyrosine kinase inhibitors in NSCLC harboring EGFR mutation and ALK translocation. Lung Cancer. 2012;77(2):460-463.

11. Shepherd FA, Rodrigues Pereira J, Ciuleanu T, et al. Erlotinib in previously treated non-small-cell lung cancer. $N$ Engl J Med. 2005;353(2): 123-132.

12. Fan Y, Xu X, Xie C. EGFR-TKI therapy for patients with brain metastases from non-small-cell lung cancer: a pooled analysis of published data. Onco Targets Ther. 2014;7:2075-2084.

13. Zhang J, Yu J, Sun X. Epidermal growth factor receptor tyrosine kinase inhibitors in the treatment of central nerve system metastases from non-small cell lung cancer. Cancer Lett. 2014;351(1):6-12.

14. Niho S, Kubota K, Nihei K, et al. Dose-escalation study of thoracic radiotherapy in combination with pemetrexed plus cisplatin followed by pemetrexed consolidation therapy in Japanese patients with locally advanced nonsquamous non-small cell lung cancer. Clin Lung Cancer. 2013;14(1):62-69.

15. Dinglin XX, Huang Y, Liu H, et al. Pemetrexed and cisplatin combination with concurrent whole brain radiotherapy in patients with brain metastases of lung adenocarcinoma: a single-arm phase II clinical trial. J Neurooncol. 2013;112(1):461-466.

16. He Y, Li S, Ren S, et al. Impact of family history of cancer on the incidence of mutation in epidermal growth factor receptor gene in nonsmall cell lung cancer patients. Lung Cancer. 2013;81(2):162-166.

17. Srivastava G, Rana V, Wallace S, et al. Risk of intracranial hemorrhage and cerebrovascular accidents in non-small cell lung cancer brain metastasis patients. J Thorac Oncol. 2009;4(3):333-337.

18. Langley RE, Stephens RJ, Nankivell M, et al. Interim data from the Medical Research Council QUARTZ trial: does whole brain radiotherapy affect the survival and quality of life of patients with brain metastases from non-small cell lung cancer? Clinical Oncol. 2013;25(3): 23-30.

19. Elaimy AL, Mackay AR, Lamoreaux WT, et al. Multimodality treatment of brain metastases: an institutional survival analysis of 275 patients. World J Surg Oncol. 2011;9:69. 
20. Pruitt AA. Medical management of patients with brain tumors. Curr Treat Options Neurol. 2011;13(4):413-426.

21. Yawn BP, Wollan PC, Schroeder C, et al. Temporal and gender-related trends in brain metastases from lung and breast cancer. Minn Med. 2003;86:32-37.

22. Carbone DP, Ding K, Roder H, et al. Prognostic and predictive role of the VeriStrat plasma test in patients with advanced non-small-cell lung cancer treated with erlotinib or placebo in the NCIC Clinical Trials Group BR.21 Trial. J Thorac Oncol. 2012;7(12):1653-1660.

23. Zhou S, Ren S, Yan L, et al. Clinical efficacy of erlotinib in patients previously treated for advanced non-small cell lung cancer. Respirology. 2009;14(5):709-715.

24. Thatcher N, Chang A, Parikh P, et al. Gefitinib plus best supportive care in previously treated patients with refractory advanced nonsmall-cell lung cancer: results from a randomised, placebo-controlled, multicentre study (Iressa Survival Evaluation in Lung Cancer). Lancet. 2005;366(9496):1527-1537.

25. Zhu CQ, da Cunha Santos G, Ding K, et al. Role of KRAS and EGFR as biomarkers of response to erlotinib in National Cancer Institute of Canada Clinical Trials Group Study BR 21. J Clin Oncol. 2008; 26(26):4268-4275.

26. Mak RH, Doran E, Muzikansky A, et al. Outcomes after combined modality therapy for EGFR-mutant and wild-type locally advanced NSCLC. Oncologist. 2011;16(6):886-895.

27. Goto K, Ichinose Y, Ohe Y, et al. Epidermal growth factor receptor mutation status in circulating free DNA in serum: from IPASS, a phase III study of gefitinib or carboplatin/paclitaxel in non-small cell lung cancer. J Thorac Oncol. 2012;7(1):115-121.

28. Togashi Y, Masago K, Fukudo M, et al. Efficacy of increased-dose erlotinib for central nervous system metastases in non-small cell lung cancer patients with epidermal growth factor receptor mutation. Cancer Chemother Pharmacol. 2011;68(4):1089-1092.

29. Porta R, Sánchez-Torres JM, Paz-Ares L, et al. Brain metastases from lung cancer responding to erlotinib: the importance of EGFR mutation. Eur Respir J. 2011;37(3):624-631.

30. Weber B, Winterdahl M, Memon A, et al. Erlotinib accumulation in brain metastases from non-small cell lung cancer: visualization by positron emission tomography in a patient harboring a mutation in the epidermal growth factor receptor. J Thorac Oncol. 2011;6(7):1287-1289.
31. Gow $\mathrm{CH}$, Chien $\mathrm{CR}$, Chang YL, et al. Radiotherapy in lung adenocarcinoma with brain metastases: effects of activating epidermal growth factor receptor mutations on clinical response. Clin Cancer Res. 2008; 14(1):162-168.

32. Yi HG, Kim HJ, Kim YJ, et al. Epidermal growth factor receptor (EGFR) tyrosine kinase inhibitors (TKIs) are effective for leptomeningeal metastasis from non-small cell lung cancer patients with sensitive EGFR mutation or other predictive factors of good response for EGFR TKI. Lung Cancer. 2009;65(1):80-84.

33. Katayama T, Shimizu J, Suda K, et al. Efficacy of erlotinib for brain and leptomeningeal metastases in patients with lung adenocarcinoma who showed initial good response to gefitinib. J Thorac Oncol. 2009;4(11): $1415-1419$

34. Wu YL, Zhou C, Cheng Y, et al. Erlotinib as second-line treatment in patients with advanced non-small-cell lung cancer and asymptomatic brain metastases: a phase II study (CTONG-0803). Ann Oncol. 2013;24(4):993-999.

35. Clarke JL, Pao W, Wu N, et al. High dose weekly erlotinib achieves therapeutic concentrations in CSF and is effective in leptomeningeal metastases from epidermal growth factor receptor mutant lung cancer. J Neurooncol. 2010;99(2):283-286.

36. Grommes C, Oxnard GR, Kris MG, et al. "Pulsatile" high-dose weekly erlotinib for CNS metastases from EGFR mutant non-small cell lung cancer. Neuro Oncol. 2011;13(12):1364-1369.

37. Ortuzar W, Hanna N, Pennella E, et al. Brain metastases as the primary site of relapse in two randomized phase III pemetrexed trials in advanced nonsmall-cell lung cancer. Clin Lung Cancer. 2012;13(1):24-30.

38. Bearz A, Garassino I, Tiseo M, et al. Activity of pemetrexed on brain metastases from non-small cell lung cancer. Lung Cancer. 2010;68(2): 264-268.

39. Barlesi F, Gervais R, Lena H, et al. Pemetrexed and cisplatin as firstline chemotherapy for advanced non-small-cell lung cancer (NSCLC) with asymptomatic inoperable brain metastases: a multicenter phase II trial (GFPC 07-01). Ann Oncol. 2011;22(11):2466-2470.
OncoTargets and Therapy

\section{Publish your work in this journal}

OncoTargets and Therapy is an international, peer-reviewed, open access journal focusing on the pathological basis of all cancers, potential targets for therapy and treatment protocols employed to improve the management of cancer patients. The journal also focuses on the impact of management programs and new therapeutic agents and protocols on

\section{Dovepress}

patient perspectives such as quality of life, adherence and satisfaction The manuscript management system is completely online and includes a very quick and fair peer-review system, which is all easy to use. Visit http://www.dovepress.com/testimonials.php to read real quotes from published authors. 